\title{
An open labeled study to evaluate efficacy and safety of ampucare in patients with bedsore
}

\author{
Janardhan Singh ${ }^{1}$, Sukhbir Singh Sangwan ${ }^{2}$, Jarnail Singh ${ }^{1}$, \\ Ram Chandar Siwach ${ }^{2}$, Govind Shukla ${ }^{3}$
}

\author{
${ }^{1}$ Department of Pharmacology, \\ ${ }^{2}$ Orthopedic Surgery, PGIMS, Rohtak- \\ 124001, India \\ ${ }^{3}$ SBMN Ayurvedic College, Rohtak, \\ India
}

Received: 17 April 2013

Received: 14 May 2013

Accepted: 20 May 2013

\section{*Correspondence to: \\ Dr. Janardhan Singh, \\ Email: dr_jansingh@yahoo.co.in}

(C) 2013 Singh J et al. This is an openaccess article distributed under the terms of the Creative Commons Attribution License, which permits unrestricted use, distribution, and reproduction in any medium, provided the original work is properly cited.

\begin{abstract}
Background: To evaluate efficacy and safety of ampucare, a polyherbal product, in patients with bedsore.

Methods: One hundred patients, either sex, more than 18 years of age, with bedsore were divided in to two groups of 50 each. Group-I- Served as control- povidone iodine solution was applied locally on the bedsore, once daily. Group- II- Treatment group- ampucare lotion was applied locally, once daily. Primary end point was time to wound healing and secondary end point included reduction in wound surface area at day-7 and at treatment completion. Percent patients cured, improved, or treatment failure were noted. Depth of wound, \% healing and adverse effects were recorded.

Results: Application of ampucare in patients with bedsore resulted in rapid healing as compared to control group. Reduction in wound surface area was significant $(p<0.01)$ in group-II. Maximum gain in thickness of granular tissue was observed in this group. In treatment group 68\% patients showed excellent response as compared to $60 \%$ in control group. Ampucare was well tolerated.

Conclusions: Ampucare treatment markedly accelerates wound healing in patients with bedsore.
\end{abstract}

Keywords: Ampucare, Bedsore, Povidone iodine, Wound healing

\section{INTRODUCTION}

Bedsores or pressure ulcers are areas of damaged skin and tissue that develop when sustained pressure cuts off circulation to vulnerable parts of body mainly skin of buttocks, hips and heels. Patients with paralysis or anyone who is bedridden are especially at risk. ${ }^{1}$ Pressure sore continues to an over present problem within our society. Prevalence of pressure ulcer in hospitalized patients has been reported to be $14-21 \%$ over the last decade. ${ }^{2}$ Pressure sores are reported to as the cause of death in $7-8 \%$ of the patients with paraplegia. ${ }^{3,4}$ Predominant age group of patients with bedsores was 71-80 years. Many factors contribute to the development of pressure sores but pressure leading to ischemia and necrosis is the final common pathway. ${ }^{5}$ Pressure exerted on the skin, soft tissue, muscle and bone by weight of the patient against the surface beneath. These pressures are often in excess of capillary filling pressure. Prolonged exposure to pressure initiates a series of events that potentially leads to tissue necrosis and ulceration. ${ }^{5}$ The inciting event is compression of the tissue against external objects such as mattress, wheelchair, pad, bed or other surface. ${ }^{6}$ Pressure, shear forces and friction can cause microcirculatory occlusion resulting in ischemia which leads to inflammation and tissue anoxia. ${ }^{6}$ Tissue anoxia leads to cell death, necrosis and ulceration. ${ }^{7}$ Muscle tissue is damaged first. Restoration of blood flow to an ischemic area of tissue reperfusion has recently been shown to cause more damage to that area causing a pressure sore to enlarge. ${ }^{8}$ The exact mechanism of ischemia reperfusion cycle of injury is not yet completely understood. ${ }^{8}$

Bedsores can develop quickly, progress rapidly and are often difficult to heal. Successful medical management of bedsore depends on the key principles including pressure reduction, adequate debridement of necrotic tissue, control of infection and meticulous wound care. ${ }^{8}$ Other treatment options of unproven efficacy include use of hyperbaric oxygen, electrotherapy and growth factors. Data on electrotherapy seems to be promising and topical application of recombinant human growth factor 'Becapler' has been for use in patients with diabetic neuropathy ulcer of the lower extremity. ${ }^{8}$ After optimal 
medical management approximately $75 \%$ of stage-II bedsores heal. However stage III and stage IV bed sores are much less likely to heal and often require surgical treatment. ${ }^{9}$ In spite of the best treatment there are recurrences and no completely safe drugs are available in the market. Medicinal herbs have been used to promote wound healing in burns and bedsores for thousands of years. ${ }^{10}$ Therefore present study was under taken to evaluate efficacy and safety of ampucare, a polyherbal product in patients with bedsores.

\section{METHODS}

After obtaining approval from the Institutional Ethical Committee, the study was carried out in Departments of Orthopedic Surgery, Paraplegic centre and Pharmacology, Postgraduate Institute of Medical Sciences, Rohtak (Haryana). One hundred patients, more than 18 years of age of either sex, with bedsores admitted in orthopedic ward or paraplegic centre were considered eligible for the study; and the exclusion criteria waspatients allergic to ampucare i.e. urticaria, hyperemia, blister, excessive burning or itching, irritation and oozing from the site of application and patients with underlying diseases that interfere with wound healing (uncontrolled diabetes mellitus, cancer, post-irradiation, immunosuppressive drugs, immunocompromised disease state).

The primary endpoint was time to wound healing, defined as epithelialization of the wound. Secondary endpoint included reduction in wound surface area on day 7 and at treatment completion, mean duration to achieve healing and percentage of patients diagnosed as cured (excellent, improved (good), failure in each arm at completion. Adverse events by clinical and laboratory assessment and patient tolerability assessment for the treatment. Healing of wound surface area; $>75 \%$ was considered as cured, 25-74\% was considered improved and $<25 \%$ was considered as treatment failure. Initial evaluation of bedsore was determined by orthopedic specialist. Clinical judgment of bedsore was used to determine the depth of the wound. Size and area of wound was recorded in $\mathrm{cm}$ at baseline before starting treatment, and on day 7 and on completion of treatment. Length and width of the wounds were measured with a ruler and wound area $\left(\mathrm{cm}^{2}\right)$ was calculated. Healing percentage of the wounds and healing time was recorded.

Healing $\%$ of wound $=$ [wound area on day-0 - wound area on day-7/ wound area on day- 0] x100

Reduction in wound area was calculated as percent of the initial wound area.

Ingredients of herbal preparation ampucare includeAzadirachta indica, Berberis aristata, Curcuma longa, Glycyrrhiza glabra, Jasminum officinale, Picrorrihiza kurroa, Pongamia pinnata, Rubia cordifolia, Saussurea lappa, Terminalia chebula, Symplocos racemosa,
Capsicum abbreviate, Nymphaea lotus, Sesamum indicum oil, Brassica juncea oil, Ricinus communis oil, Cupric sulphate and Bees wax.

\section{Study Overview}

An open label, randomized, active control, parallel group clinical study was conducted comparing topical application of ampucare ( $5 \mathrm{ml}$ lotion) versus povidone iodine solution on bed sores. Recruited patients were randomly allocated to one of the two treatments groups according to computer generated randomization list in the allocation ratio of 2:1. Bedsores were properly cleaned with hydrogen peroxide solution and then saline solution. Ampucare lotion $5 \mathrm{ml}$ or povidone iodine solution was applied locally, directly and spread over the wound with cotton swab followed by dressing of the wound as required. Treatment with topical agents (ampucare vs povidone iodine) was continued till the bedsores were fully healed and epithelialized. At the time of each dressing the wound was observed clinically for signs of infection, size, rate and nature of epithelialization by an expert surgeon. No other topical agents or dressing was permitted. All patients received standard treatment protocols during hospitalization, oral or injectable antibiotics, mechanical devices i.e. tractions, POP for treatment of fractures, analgesics were allowed. Blood transfusions were given on as required basis and the record was maintained. Patients' response regarding side effects of treatment was recorded.

Sample size and statistical analysis: In this study 100 patients were enrolled with 50 each in control (povidone iodine) and ampucare treatment groups. Results were analyzed statistically using unpaired Student's “ $t$ " test. A p value of $<0.05$ was considered to be statistically significant.

\section{RESULTS}

Application of ampucare lotion in patients with bedsore resulted in a rapid and early healing as compared to control. In Group-I- control (povidone iodine) group mean healing time was $39.80 \pm 4.84$ days as compared to $33.58 \pm 3.69$ days in ampucare treated group. Thus wound healing was approximately earlier by 6 days in the Group-II (Table 1) In Group-1 mean area of wound was $61.91 \pm 6.83 \mathrm{~mm}^{2}$ on day $0,34.65 \pm 6.95 \mathrm{~mm}^{2}$ on day 7 and $10.97 \pm 3.28 \mathrm{~mm}^{2}$ on completion of the study. Reduction in wound surface area in ampucare treated group was significant $(\mathrm{p}<0.01)$ as compared to control group. Results of the study indicate that ampucare solution markedly accelerated wound closure rate in patients with bedsore as compared to povidone iodine. The maximum gain in thickness of granulation tissue was observed in Group-II as compared to control. In Group-I percent healing observed was 44.03 on day-7 and $82.88 \%$ on completion of the study (at the time of discharge of patient from hospital) and in Group-II (ampucare 
treatment), percent healing was 59.38 on day-7 and $92.86 \%$ on completion of the study.

In group-I, $60 \%$ subjects showed an excellent response or were cured (healing area more than > 75\%), 26\% showed an improvement or a good response (healing area $25-74 \%$ ) and treatment failure (response $<25 \%$ ) in $14 \%$ subjects. On the other hand in Group-II, an excellent response was seen in $68 \%$ subjects, $26 \%$ improved and $6 \%$ had failed to respond. Ampucare was well tolerated because no clinically important adverse drug reaction was observed/ reported during the study. Some pictures are also showing beneficial effect of local application of ampucare in patients with bedsore.

Table 1. Effect of ampucare lotion on wound area $\left(\mathrm{mm}^{2}\right)$ in patients with bedsore on day-0, day-7 and on completion of study. Data reported as mean \pm S.E.

\begin{tabular}{|llllll|}
\hline Sr. No. & Groups & Day-0 & Day-7 & \multicolumn{2}{l|}{ Completion of the study } \\
\hline 1. & I- (povidone iodine) & $61.91 \pm 6.83$ & $34.65 \pm 6.95$ & $10.97 \pm 3.28$ & $39.80 \pm 4.84$ \\
\hline 2. & II- (ampucare)) & $56.31 \pm 7.06$ & $25.91 \pm 5.14^{*}$ & $4.02 \pm 1.88^{*}$ & $33.58 \pm 3.69^{*}$ \\
\hline
\end{tabular}

$\mathrm{p}<0.01$ when compared with control (unpaired Student's " $\mathrm{t}$ " test).

\section{Photographs showing effect of Ampucare treatment in Patients with bedsore.}

Before treatment
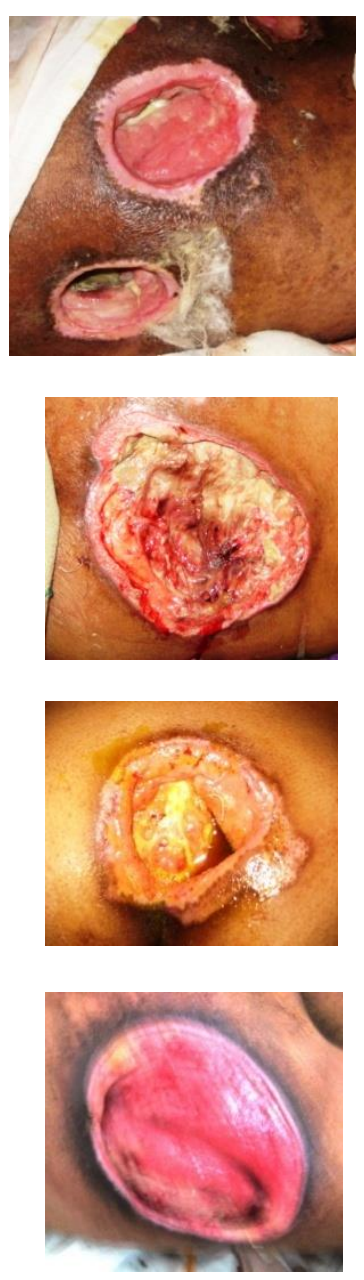

After treatment
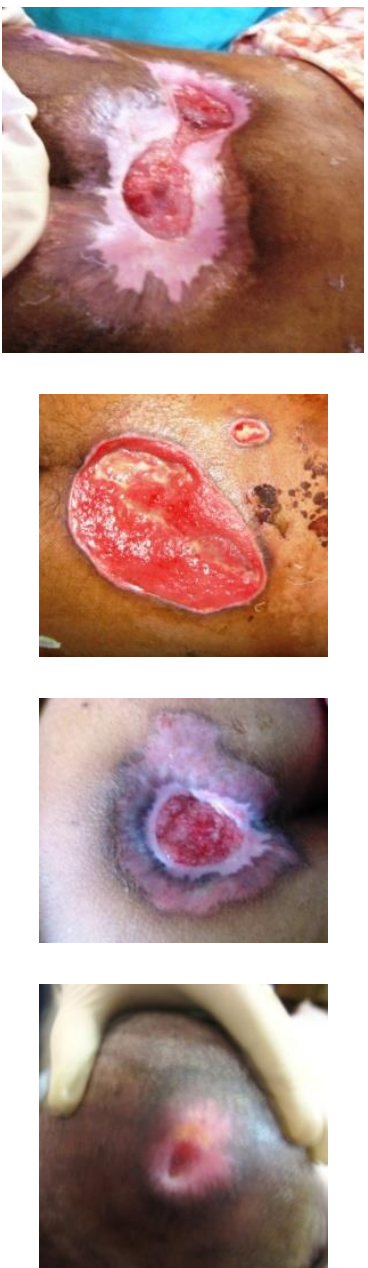
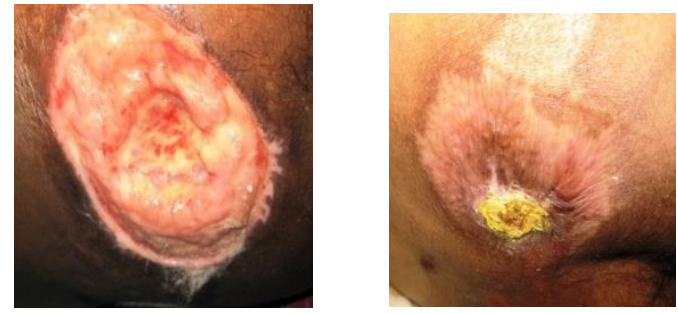

\section{DISCUSSION}

In the study, comparative evaluation of topically applied polyherbal preparation ampucare with povidone iodine demonstrated a statistically significant reduction in time to heal the bedsores. This parameter is a major indicator of successful therapy of bedsore. In addition the study showed that ampucare was well tolerated and safe topically. No important adverse drug reaction such as allergic reactions, itching, irritation or redness were reported during the study. Beneficial effects of ampucare over povidone iodine in the process of healing of bedsore may be due to its vasodilator, antimicrobial, antiinflammatory, antioxidant and immunomodulatory properties. Ingredients of ampucare like Jasminum officinale, Pongamia pinnata, Rubia cordifolia, Terminalia chebula etc. have been shown to accelerate wound healing by various mechanisms. Counterirritant or rubefacient properties of capsicum abbreviate and Brassica juncea could increase blood flow to the site of application via vasodilatation, the property which is very important in accelerating bedsore healing since sustained pressure cuts off circulation to the vulnerable part of the body.

Antimicrobial effect of povidone iodine is the only mechanism justifying its continued use for wound care. In ampucare herbs like A. indica, B. aristata, C. longa, $P$. 
kurroa, P. pinnata, Rubia cordifolia, T. chebula, Symplocos racemosa and Jasminum officinale have been reported to possess good antimicrobial activity. ${ }^{11}$ Thus, antimicrobial activity of natural products ${ }^{12}$ helps in reducing infection in the wound area and the surrounding skin and ultimately promotes early healing of bed sore. The wound is rich in oxidants such as hydrogen peroxide. Over production of reactive oxygen species (ROS) results in oxidative stress, thereby causing cytotoxicity and delayed wound healing. Various ingredients of ampucare have been shown to possess antioxidant properties ${ }^{13}$ and free radical scavenging properties ${ }^{14,15}$ which are beneficial in accelerating healing of bedsores. Since inflammation and thus various inflammatory mediators are involved in the process of wound healing the reported anti-inflammatory activity of many herbs in ampucare may help in healing of pressure ulcers. Immunomodulatory and immunostimulant properties ${ }^{16,17}$ have been reported for P. kurroa and S. lappa may be helpful in accelerating healing of the bedsore.

\section{ACKNOWLEDGEMENTS}

Authors are grateful to M/S Venous Remedies Limited, Baddi (Himachal Pradesh) India, for providing gift samples of ampucare for this study.

Funding: No funding sources

Conflict of interest: None declared

Ethical approval: The study was approved by the institutional ethical committee

\section{REFERENCES}

1. Russel RCG, Williams NS, Bulstrode CJK, Arnold H. In "Bailey and Love'S Short Practice of Surgery" 24 ${ }^{\text {th }}$ eds. 2004: pp. 939.

2. Amlung SR, Miller WL, Bosley LM. The National Pressure ulcer prevalence survey: a bench marking approach. Adv. Skin wound care 2001;14 (6)297301.

3. Giallagher SM. Outcomes in clinical practice: Pressure ulcer prevalence and incidence studies. Ostomy Wound Manage 1997;43(1):28-32, 34-35, $38-40$.

4. Kenkel JM. Pressure sores (overview). In: Kenkel JM. Selected Read Plast Surg. Vol 8, No. 39, Texas: Baylor University Medical Center 1998: pp 1-29.
5. Reuler JB, Cooney TG. The pressure sore: pathophysiology and principles of management. Ann Intern Med 1981; 94: 661-6.

6. Klitzman B, Kalinowski C, Gilasofer SL, Rugani L. Pressure ulcers and pressure relief surfaces. Clin Plast Surg 1998; 25: 443-50.

7. Kirker KR, Secor PR, James AA et al. loss of viability and induction of apoptosis in human keratinocytes exposed to Staphylococcus aureus biofilms in vitro. Wound Repair Regen 2009; 17 (5): 690-9.

8. Kirman CN, Molnar JA. Pressure ulcers, nonsurgical treatment and principles. http://emedicine.medscape.com/article/12936142010. 1-19.

9. Woolsey RM, Mcgarry JD. The cause prevention and treatment of pressure sores. Neurol. Clin 1991; 9 (3):797-808.

10. http://floraleads.com/sore. Traditional herbal remedy for wounds and sores. 1-5.

11. Chopra RN, Chopra IC, Handa KL, Kapur LD. In "Indigenous drugs of India" . UN Dhur and sons, private Ltd. Calcutta. 1958 ; p 1- 816.

12. Srivastava SM, Kumar S, Chaudhary M. time kill curve studies of ampucare against Eschrechia coli, Staphylococus aureus, klebsiella pneumonia and Proteus vulgaris. Res J Medic Plant 2009;3:116-22.

13. Dwivedi VK, Chaudhary M, Soni A, naithani V, Srivastava SM. Therapeutic role of ampucare in alternations of antioxidant enzyme activities and wound healing effect in Mus musculus mice. J Ecophyio Occup Health 2008;8:167-76.

14. Govindarajan R, Vijaya Kumar M, Rawat AKS, Mehrotra S. Free scavenging potential of Picrorrhiza kurroa Royle ex Benth. Indian J Exp Biol 2003;41:875-9.

15. Nagatsu A, Sugitani T, Mori Y, okuyama $H$, Sahakiboora J, Hizukami H. Antioxidants from rape 9 Brassica coompestris viv Japonica hara0 or cake. Natural Product Res 2004;18(3):231.

16. Kulkarni S, Desai S. Immunostimulant activity of insulin isolated from Sauussurea lappa root. Indian J. Pharmaceut. Sci. 2001;62:292-4.

17. Labadie RP. An ethnopharmacognostic approach to the search for immunomodulators of plant origin. Planta Medica 1989;55:339-48.

doi:10.5455/2319-2003.ijbcp20130805

Cite this article as: Singh J, Sangwan SS, Singh J, Siwach RC, Shukla G. An open labeled study to evaluate efficacy and safety of ampucare in patients with bedsore. Int J Basic Clin Pharmacol 2013;2:3714. 